\title{
Genetic diversity of Plasmodium falciparum isolates from patients with uncomplicated and severe malaria based on $m s p-1$ and $m s p-2$ genes in Gublak, North West Ethiopia
}

\author{
Hussein Mohammed ${ }^{1 *}\left(\mathbb{D}\right.$, Kedir Hassen ${ }^{1}$, Ashenafi Assefa ${ }^{1}$, Kalkidan Mekete$^{1}$, Gemechu Tadesse $^{1}$, Girum Taye ${ }^{1}$
} and Robert J. Commons ${ }^{2,3}$

\begin{abstract}
Background: Malaria infection can present with a wide variety of symptoms, ranging from mild to severe. Plasmodium falciparum isolates in uncomplicated and severe malaria infections may have different parasite genetic profiles. This study was conducted to assess differences in genetic diversity and allelic frequencies in P. falciparum isolates according to malaria severity and age of patients in the Gublack area, northwest Ethiopia.
\end{abstract}

Methods: Cross-sectional health facility-based study conducted in Gublak, Ethiopia between July, 2017 and October, 2017. Symptomatic P. falciparum malaria patients with microscopically-confirmed infection were enrolled. Parasite DNA was extracted from filter paper blood spots and the polymorphic regions of the msp- 1 and msp- 2 genes were genotyped using allele-specific nested-PCR with fragment analysis by gel electrophoresis.

Results: A total of 118 patients were enrolled including 95 (80.5\%) with uncomplicated infection and 23 (19.5\%) with severe disease. In msp-1, the K1 allelic family was similarly prevalent in uncomplicated 42 (44.2\%) and severe disease 12 (52.2\%). In msp-2, FC27 was detected in 55 (57.9\%) of uncomplicated infections and IC/3D7 in 14 (60.9\%) of severe infections. 76 (64.4\%) of the 118 isolates contained multiple genotypes; 56 (58.9\%) in uncomplicated infections and 19 $(82.6 \%)$ in severe infections. The overall of multiplicity of infection was $2.2(95 \% \mathrm{Cl} 1.98-2.42)$ with $1.4(95 \% \mathrm{Cl} 1.23-$ $1.55)$ and 1.7 (95\% Cl 1.49-1.86) for $m s p-1$ and $m s p-2$, respectively. Multiplicity of infection was significantly higher in severe than uncomplicated infections $(3.0(95 \% \mathrm{Cl} 2.61-3.47)$ versus $2.0(95 \% \mathrm{Cl} 1.83-2.23)$, respectively, $p=0.001)$. There was no difference in multiplicity of infection across age groups $(p=0.104)$.

Conclusion: Patients with severe malaria were more likely to have multiclonal infections. Further studies are needed to describe the association between P. falciparum genotypes and malaria severity in different malaria transmission areas.

Keywords: Plasmodium falciparum, Ethiopia, Genetic diversity, Merozoite surface protein, Disease severity

\section{Background}

Severe malaria is a major public health problem. Globally about 3.3 billion people live in malaria endemic areas, despite improvements in the implementation of effective control measures. Each year, there are an estimated 219

*Correspondence: Hussein_ehnri@yahoo.com

${ }^{1}$ Ethiopian Public Health Institute, Addis Ababa, Ethiopia

Full list of author information is available at the end of the article million clinical malaria cases and 435,000 deaths worldwide, the majority of which occur in sub-Saharan Africa [1]. Approximately $60 \%$ of the Ethiopian population live in malaria-endemic areas $[2,3]$.

Of the Plasmodium species that cause human malaria, Plasmodium falciparum is the main cause of severe malaria and malaria-associated deaths [4]. Severe malaria is differentiated from uncomplicated malaria by a set of diagnostic criteria including clinical 
and laboratory criteria [5]. The infective load is greater with $P$. falciparum than other malaria species and its propensity to sequester in capillaries leads to increased morbidity [6, 7]. However, the host-parasite factors leading to severe disease or death as compared to uncomplicated disease are not completely understood; these include parasite factors such as genetic diversity and multiplicity of infection (MOI).

Numerous studies have characterized strains of P. falciparum isolates using genetic polymorphisms as markers [8-11]. Merozoite surface protein ( $m s p)$ genes are the most commonly used markers of $P$. falciparum due to their high polymorphism. MSP-1 and MSP-2 are $P$. falciparum blood-stage malaria vaccine targets [12] and are also suitable markers for identification of genetically distinct $P$. falciparum parasite subpopulations. MSP-1 is major surface protein encoded by $m s p-1$ on chromosome 9 , which contains 17 blocks of sequences flanked by conserved regions. It plays a major role in erythrocyte invasion [13] and is targeted by immune responses [14]. Block 2, which is the most polymorphic part of $m s p-1$, is grouped under three allelic families of K1, MAD20 and RO33 [15]. MSP-2 is a glycoprotein encoded by the $m s p-2$ gene located on chromosome 2 and is composed of five blocks of which the central block is the most polymorphic. The $m s p$ 2 block 3 alleles are grouped into two allelic families, FC27 and IC3D7 [16]. Genotyping polymorphic regions of $P$. falciparum are important to determine diversity and multiplicity of P. falciparum infection [17]. Genetic diversity of $P$. falciparum populations and MOI vary according to the intensity of transmission, outcome of infections and age in different geographical regions [18]. In areas of high malaria transmission, parasite diversity and MOI are increased $[4,18]$.

Some specific $P$. falciparum genotypes have been associated with severe malaria in epidemiological studies [19]. Severe malaria has also been associated with highly polymorphic parasites [10] and multiclonal parasites [11]. In comparison, other studies have observed a lower frequency of multiclonal infections in $P$. falciparum isolates from patients with severe malaria $[20,21]$. Only a few studies have reported on the genetic diversity and clonality of $P$. falciparum in Ethiopia [22-24]. These studies have investigated isolates from uncomplicated symptomatic malaria. Thus, investigation of the $m s p-1$ and $m s p-2$ genes from isolates of patients with severe malaria in Ethiopia is important to obtain knowledge about parasite-factors associated with virulence in Ethiopia. This study aims to explore whether $P$. falciparum genetic diversity and multiclonality are associated with disease severity and age of patients in Gublack area, northwest Ethiopia.

\section{Methods}

\section{Study site}

A cross sectional health facility-based study was carried out in Gublak Health Center, Dangure district, Benishangul-Gumuz Regional State northwest Ethiopia (Fig. 1). The study area is located $589 \mathrm{kms}$ from Addis Ababa and has a catchment population of estimated 12,088 inhabitants. The area is located at $11^{\circ} 18^{\prime} \mathrm{N}$ latitude, $35^{\circ} 99^{\prime} \mathrm{E}$ longitude at an altitude of $886 \mathrm{~m}$ above sea level. $P$. falciparum is the predominant species and Anopheles arabiensis is the major vector. The Benishangul-Gumuz region had the highest risks of malaria compared to other regions, and also malaria burden is higher in-migrant labourers coming from nearby highland areas $[25,26]$. Malaria transmission in the area is relatively high with all age groups in the population at risk of the disease [27]. The average 3 years of the district malaria positivity rates reported by microscopy to be $64 \%$ (unpublished document).

\section{Study population and blood samples collection}

A total of 118 P. falciparum infected blood samples were collected from children and adults presenting to the Gublak Health Center and enrolled into the study from July, 2017 to October, 2017. Patients were classified into uncomplicated and severe malaria according to World Health Organization (WHO) criteria [28]. The inclusion criteria for mild (uncomplicated) malaria cases were fever (axillary temperature $\geq 37.5^{\circ} \mathrm{C}$ ) or history of fever in the previous $24 \mathrm{~h}$, malaria density $<100,000$ parasites/ $\mu \mathrm{L}$ and absence of danger signs or evidence of severe malaria. Severe malaria cases were defined by additional symptoms such as: convulsion, clinical jaundice, respiratory distress, hyperparasitaemia $(>100,000$ asexual parasites $/ \mu \mathrm{L}$ ) and severe anemia (hemoglobin level $<5 \mathrm{~g} /$ $\mathrm{dL}$ ). Severe malaria patients were admitted to the health center and treated according to the national treatment guidelines [29].

Capillary blood was obtained from a finger prick from each patient and used to prepare thick and thin blood smears. Thick and thin blood smears were air dried and stained with $10 \%$ fresh Giemsa for $15 \mathrm{~min}$. All slides were examined by two independent laboratory technicians to determine malaria species and the parasite density. In case of discordance the slides were read by a third laboratory technician. The density of parasitaemia was expressed as the number of asexual parasites per microlitre of blood, assuming a leukocyte count of $8000 / \mu \mathrm{L}$ of blood [30]. Blood smears were considered negative when no parasites were present after the examination of 200 oil immersion fields on a thick blood film. After consent was obtained, the haemoglobin concentration was measured using a portable spectrophotometer $\left(\mathrm{HemoCue}{ }^{\circledR}\right.$, 

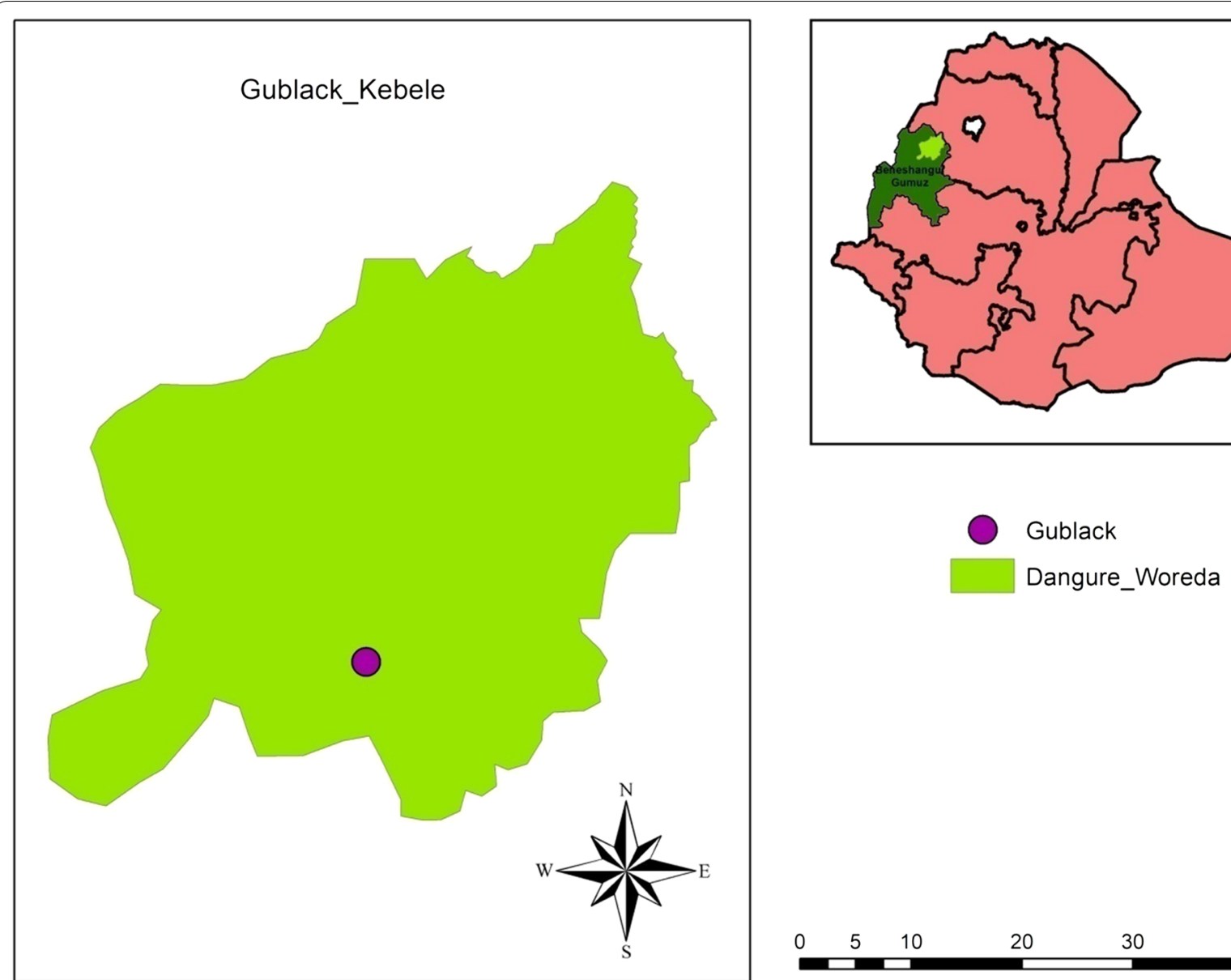

Fig. 1 Map of the sample collection area, Gublak, North West Ethiopia. Purple colour indicated the sampling site

Angelholm, Sweden). The blood was spotted onto Whatman $903^{\circledR}$ filter paper (Schleicher \& Schuell Bio Science, Keene, NH 03431, USA), air-dried and individually placed into a plastic bag with silica gel. These dried blood spots were transported and stored to the Malaria Research Laboratory (Ethiopian Public Health Institute) at Addis Ababa, Ethiopia.

\section{Extraction of parasite DNA and genotyping of Plasmodium falciparum msp-1 and $m s p-2$ genes}

Parasite DNA was extracted from the blood spots collected on filter papers using the Chelex $-100^{\circledR}$ (Bio-Rad Laboratories CA) method [31], with a final volume of $200 \mu \mathrm{L}$ for each sample and storage at $-20{ }^{\circ} \mathrm{C}$ until it was used for the amplification reaction. Allelic genotyping of the $P$. falciparum merozoite surface protein 1 ( $m s p 1$ ) (block2) and 2 ( $m s p 2$ ) (block 3 ) was carried out as previously described [22]. Monoclonal infections were defined by detection of a single PCR fragment for each locus, with polyclonal infection defined if more than one fragment was identified. Multiplicity of infection (MOI) was defined as the average number of different genotypes per infected patient.

\section{Statistical analysis}

Data were entered and analysed using SPSS version 20 (SPSS Inc. Chicago, IL, USA). The $m s p-1$ and $m s p-2$ allelic frequencies were calculated. The mean multiplicity of infection (MOI) was calculated for $m s p-1, m s p-2$ and overall. The mean MOI was compared between uncomplicated and severe malaria cases using the non-parametric Mann-Whitney U test. The proportion of alleles observed at each locus within each group were compared using Chi-square test statistic. Spearman's rank correlation coefficient was used to assess the relationships between continuous variables. A p-value less than 0.05 was considered significant.

\section{Ethical consideration}

The study received ethical approval from the Scientific and Ethical Review Office (SERO) of the Ethiopian Public Health Institute (EPHI). Written consent was obtained 
from the patients and guardians, and malaria positive individuals were treated in accordance with the national malaria guidelines [29].

\section{Results}

\section{Demographic and parasitological data}

The study population comprised 118 microscopically confirmed P. falciparum patients of whom 95 (80.5\%) had uncomplicated malaria and 23 (19.5\%) severe malaria. The major clinical manifestations of the patients are shown in Table 1. The geometric mean parasite density was higher in severe malaria compared to uncomplicated malaria patients (3638 vs. 116,502 parasites $/ \mu \mathrm{L})$, and this difference was statistically significant $(\mathrm{p}=0.01)$. Bed net coverage was $24.6 \%(29 / 118)$ among the confirmed malaria cases.
Allelic frequency, genetic diversity and multiplicity of infection of $P$. falciparum in uncomplicated and severe malaria patients

A total of 180 samples positive for $P$. falciparum were genotyped using MSP1 (block 2) and MSP2 (block 3) by nested PCR and the magnitude of alleles were classified based on their fragments size (Additional file 1: Figure S1; Additional file 2: Figure S2). Of these, 85 (72\%) and 95 (80.5\%) were positive for MSP1 and MSP2, respectively. Among the msp-1 isolates, the proportion of K1, MAD20 and RO33 allelic families were 54 (45.8\%), 26 (22.0\%) and $32(27.1 \%)$, respectively. And the $m s p-2$ alleles, the frequency of FC27 allelic family was 58.5\% (69/118) and IC/3D7 type was $49.2 \%(58 / 118)$.

The distribution of detected $m s p-1$ and $m s p-2$ allelic families in uncomplicated and severe malaria patients is presented in Table 2 . The total number of detected alleles

Table 1 Demographics and clinical features of uncomplicated and severe malaria patients in Gublak, North West, Ethiopia

\begin{tabular}{|c|c|c|}
\hline Characteristic & Uncomplicated malaria $(n=95)$ & $\begin{array}{l}\text { Severe } \\
\text { malaria } \\
(n=23)\end{array}$ \\
\hline Age, years (mean $\pm S D$ ) & $16.1 \pm 9.5$ & $17.0 \pm 10.9$ \\
\hline Sex ratio (male/female) & $0.86(44 / 51)$ & $1.6(14 / 9)$ \\
\hline Axillary temperature, ${ }^{\circ} \mathrm{C}$ (mean $\left.\pm \mathrm{SD}\right),{ }^{\circ} \mathrm{C}$ & $37.6 \pm 0.36$ & $38.2 \pm 0.83$ \\
\hline Geometric mean parasitaemia, $/ \mu \mathrm{L}$ & 5724 & 59,214 \\
\hline Hyperparasitaemia, > 100,000 parasites/uL (n (\%)) & $0(0.0 \%)$ & $19(82.6 \%)$ \\
\hline Convulsions (n (\%)) & $0(0.0 \%)$ & $3(13.0 \%)$ \\
\hline Clinical jaundice (n (\%)) & $0(0.0 \%)$ & $3(13.0 \%)$ \\
\hline Baseline haemoglobin, $\mathrm{g} / \mathrm{dL}$ (mean $\pm \mathrm{SD}$ ) & $11.8( \pm 1.8)$ & $8.6( \pm 1.7)$ \\
\hline Severe anaemia, < 5 g/dL (n (\%)) & $0(0.0 \%)$ & $2(8.7 \%)$ \\
\hline
\end{tabular}

$S D$ standard deviation; $\mu \mathrm{L}=$ microlitre

Table 2 Allelic frequency of $m s p-1$ and $m s p-2$ in uncomplicated and severe malaria patients in Gublak, North West, Ethiopia

\begin{tabular}{|c|c|c|c|c|c|c|c|}
\hline \multirow[t]{2}{*}{ Allele } & \multicolumn{3}{|c|}{ Uncomplicated malaria $(n=95)$} & \multicolumn{3}{|c|}{ Severe malaria $(n=23)$} & \multirow[t]{2}{*}{ p-value* } \\
\hline & n (\%) & Fragment size (bp) & No. of alleles & n (\%) & Fragment size (bp) & No. of alleles & \\
\hline \multicolumn{8}{|l|}{ MSP-1 } \\
\hline $\mathrm{K} 1$ & $30(31.6)$ & $110-350$ & 10 & $2(8.7)$ & $110-250$ & 4 & \\
\hline MAD20 & $7(7.4)$ & $130-350$ & 6 & $2(8.7)$ & $150-300$ & 4 & \\
\hline $\mathrm{RO} 33$ & $13(13.7)$ & $150-200$ & 3 & $5(21.7)$ & $150-200$ & 3 & \\
\hline Total & $65(68.4)$ & & 19 & $20(86.9)$ & & 11 & 0.015 \\
\hline \multicolumn{8}{|l|}{ MSP-2 } \\
\hline FC27 & $31(32.6)$ & $250-550$ & 9 & $6(26.1)$ & $250-500$ & 7 & \\
\hline IC/3D7 & $19(20)$ & $300-700$ & 13 & $7(30.4)$ & $300-500$ & 6 & \\
\hline Total & $73(76.8)$ & & 22 & $22(95.7)$ & & 13 & 0.138 \\
\hline Overall MOI & & & 2.0 & & & 3.0 & \\
\hline
\end{tabular}

$n$ number of positive individuals, $\mathrm{MOI}$ multiplicity of infection, total total number of fragments and distinct clones

* p-value calculated by Chi-square test 
in uncomplicated malaria patients were 19 and 22 for $m s p-1$ and $m s p-2$, respectively. In severe malaria patients, a total of 11 different alleles were detected for $m s p$ - 1 and 13 different alleles for $m s p$-2. Of the 118 P. falciparum isolates, $76(64.4 \%)$ harboured more than one parasite genotype (Table 4). Among the multiple infections, 57 $(60.0 \%)$ and 19 (80.6\%) were detected in uncomplicated malaria and severe malaria cases, respectively. Neither msp1 nor $m s p 2$ allelic families were associated with severe malaria cases (Table 2).

The overall mean multiplicity of infection was 2.2 (95\% CI 1.99-2.42). The mean MOIs for uncomplicated and severe malaria patients were 2.0 (95\% CI 1.79-2.23) and 3.0 (95\% CI 2.4-3.59), respectively, which was statistically significant $(p=0.001)$. The mean MOI was highest (2.6, 95\% CI 2.06-3.11) among the youngest age groups ( $<5$ years old) (Table 3 ) but this was not statistically significant $(p=0.104)$. The youngest age group had the highest mean parasite density $(36,345.3$ parasites $/ \mu \mathrm{L})$ compared to that of older age groups (21,334.2 parasites/ $\mu \mathrm{L}$ ) (Table 4). However, the differences in parasitaemia between these age groups were not statistically significant $(p=0.09)$.

\section{Discussion}

Investigating the association between $P$. falciparum genetic profiles and clinical outcome potentially provides important information for predicting diseaserelated outcomes in malaria endemic areas. This is the first study that has investigated the association between disease severity, and genetic diversity and multiplicity of infection using the two most polymorphic regions of $m s p-1$ and $m s p-2$ in northwestern Ethiopia. The $m s p$ genes are usually used for $P$. falciparum population genetics in spite of limitations of the impact of human immune selection [32]. The findings suggest that

Table 3 Distribution of Plasmodium falciparum of $m s p-1$ and $m s p-2$ allelic families by age

\begin{tabular}{|c|c|c|c|c|}
\hline \multirow[t]{2}{*}{ Allele } & \multicolumn{4}{|l|}{ Age group (years) } \\
\hline & $0-5, n(\%)(n=24)$ & $6-15, n(\%)(n=14)$ & $>15, n(\%)(n=80)$ & $\begin{array}{l}\text { Total, } n(\%) \\
(n=118)\end{array}$ \\
\hline \multicolumn{5}{|l|}{ MSP-1 } \\
\hline K1 & $8(33.3)$ & $2(14.3)$ & $22(27.5)$ & $32(37.7)$ \\
\hline MAD20 & $4(16.7)$ & $2(14.3)$ & $3(3.7)$ & 9 (10.6) \\
\hline $\mathrm{RO} 33$ & $2(8.3)$ & $3(21.4)$ & $13(16.3)$ & $18(21.2)$ \\
\hline $\mathrm{K} 1+\mathrm{MAD} 20$ & $3(12.5)$ & $2(14.3)$ & $7(8.8)$ & $12(14.1)$ \\
\hline $\mathrm{K} 1+\mathrm{RO} 33$ & $1(4.2)$ & $1(7.1)$ & $6(7.5)$ & $8(9.4)$ \\
\hline $\mathrm{MAD} 20+\mathrm{RO} 33$ & $2(8.3)$ & $0(0.0)$ & $1(1.2)$ & $3(3.5)$ \\
\hline $\mathrm{K} 1+\mathrm{MAD} 20+\mathrm{RO} 33$ & $2(8.3)$ & $0(0.0)$ & $1(1.2)$ & $3(3.5)$ \\
\hline Total & $22(91.7)$ & $10(71.4)$ & $53(66.2)$ & $85(100)$ \\
\hline \multicolumn{5}{|l|}{ MSP-2 } \\
\hline FC27 & $9(37.5)$ & $2(14.3)$ & $26(32.5)$ & 37 (38.9) \\
\hline IC/3D7 & $3(12.5)$ & $4(28.6)$ & $19(23.7)$ & $26(27.4)$ \\
\hline $\mathrm{FC} 27+\mathrm{IC} / 3 \mathrm{D} 7$ & $8(33.3)$ & $6(28.6)$ & $18(22.5)$ & $32(33.7)$ \\
\hline Total & $20(83.3)$ & $12(85.7)$ & $63(78.7)$ & $95(100)$ \\
\hline
\end{tabular}

$n$ number of individuals

Table 4 Distribution of multiple genotypes, mean multiplicity of infection, and parasitaemia by age group of $P$. falciparum malaria patients in Gublak, Ethiopia

\begin{tabular}{|c|c|c|c|c|}
\hline \multirow[t]{2}{*}{ Characteristics } & \multicolumn{4}{|c|}{ Age group (years) } \\
\hline & $0-5(n=24)$ & $6-15(n=14)$ & $>15(n=80)$ & Total $(n=118)$ \\
\hline Mild malaria, n (\%) & $17(70.8)$ & $13(92.9)$ & $65(81.2)$ & $95(80.5)$ \\
\hline Severe malaria, n (\%) & $7(29.2)$ & $1(7.1)$ & $15(18.8)$ & $23(19.5)$ \\
\hline Multiple P. falciparum genotypes, n (\%) & $19(79.1)$ & $9(64.3)$ & $48(60.0)$ & $76(64.4)$ \\
\hline Mean $\mathrm{MOI}$ & 2.6 & 2.4 & 2.1 & 2.2 \\
\hline $\begin{array}{l}\text { Mean parasitaemia (number of } P \text {. falciparum para- } \\
\text { sites } / \mu \mathrm{L} \text { of blood) }\end{array}$ & $36,345.3$ & $20,875.4$ & $21,334.2$ & $24,332.9$ \\
\hline
\end{tabular}


malaria transmission is high in the study area despite efforts of intensive control measures. The authors also identified a greater propensity for multiclonal infections in patients with severe disease.

Associations between the dominant allelic families and disease severity were examined. In $m s p-1$, the K1 allelic family was identified in similar proportions in uncomplicated and severe malaria. This differs to previous studies in Senegal where the K1 allelic family had been associated with severe malaria [33]. This difference may be due to differences in malaria endemicity or the small size of the current study, particularly in the severe malaria cases. The prevalence of two $m s p-2$ families were also similar between uncomplicated and severe disease, which is similar to the previous reports elsewhere [34, 35].

The study identified a higher proportion of $m s p-2$ than $m s p-1$, which is similar to a study conducted in Sudan [9]. The current study found a high genetic diversity in parasites circulating in the study area with a total of 19 and 22 genotypes for $m s p-1$ and $m s p-2$, respectively. These findings are similar to those study reported from Senegal [36]. The presence of more genetic diversity in the current study area is likely to be an outcome of the presence of more parasite population, that resulted in mixing of genotypes.

The current study also found a high frequency (64\%) of patients with multiclonal infections, which is in line with the previous studies from Ethiopia [22] and Sudan [37]. In contrast, studies from West Africa including the Republic of Congo [38] and Nigeria [39], found a lower frequency of patients with multiclonal infections. This variation likely reflects differences in geographic variability, parasite epidemiology and transmission. The frequency of multiclonal infections has also been reported to increase with age until late childhood before declining [40]. The results were consistent with this finding, with multiclonal infections more prevalent in younger children.

The mean number of circulating genotypes in severe malaria patients was higher than from patients with uncomplicated malaria. Similar results have been observed among patients with severe malaria in Uganda [8]. Studies from Madagascar, Gabon and Sudan $[20,34,35]$ showed no differences in uncomplicated or severe malaria cases. However, a study from Nigeria reported a low a multiplicity of $P$. falciparum infection in individuals with severe malaria [41]. These differences may also be related to the immune status of the study population, considerable immigrant labourers were observed in the study area. Moreover, this could also be due to the differences in genotyping methods and interpretation of result, and the heterogeneity of the study populations may suggest the inconsistency variability of results between studies.

Age is a key factor involved in the acquisition of immunity against falciparum malaria and has been found to influence MOI [8]. In turn, the low levels of acquired immunity in young children may be a major factor contributing to their vulnerability to control the infection [42, 43]. Although the mean MOI decrease with age was observed in the current study this was not statistically significant. These results complements the findings from Ethiopia [22], Republic of Congo [38], Senegal [44], and south of Benin [45], but contrast with a study from Tanzania [43]. The lack of a significant trend is potentially limited by power due to the relatively small number of patients younger than 15 years. The high level of malaria transmission in the region may be expected to lead to a higher risk of severe malaria in younger patients where immunity is lower [9], however, the mean age of the patients with uncomplicated and severe malaria was similar.

Bed nets are an important tool for prevention of the malaria vector and are widely used in malaria endemic areas of the Ethiopia. Reduced MOI has observed to be associated with increased ITN use, which is consistent with being an indicator of transmission intensity [46]. The present study found a low utilization of bed nets (24.6\%), which might be due to the location of the study area, where there are mechanized farms with migrant labourers sleeping in open fields or temporary shelters [25]. This poor uptake of bed nets might be an important factor contributing to the increased the MOI, with labourers at high risk of developing malaria infection in this area.

Consistent with previous studies, the current study found no association between the frequency of specific P. falciparum alleles and disease severity [12, 35]. Limitations in the current study include the small number of patients with severe disease and the use of nested PCR instead of microsatellites or DNA sequencing which could potentially underestimate genetic diversity. Furthermore, with the rapid temporal changes in parasite density and maturity due to parasite sequestration, a single peripheral blood sample may not reveal the full complexity of the parasite population harbored by individuals [47]. In addition, low frequency alleles at the time of blood sampling may not have been detected by nested PCR. Future studies need to be designed to take large sample sizes and use more robust techniques to study the relationship between genetic diversity and malaria severity. 


\section{Conclusion}

The present study demonstrates a high multiplicity of $P$. falciparum infections in severe malaria isolates in Gublack, North West Ethiopia. While the MOI was highest among young children, there was no significant difference between MOI amongst age groups. The high MOI and diversity of $P$. falciparum populations in this region could be related to the low utilization of the ITNs. These findings suggested that implementation of customized tools to prevent malaria transmission, by targeting migrant laborers, which substantially improves malaria control in the region. Further longitudinal studies on malaria severity with larger sample sizes in different malaria endemic areas of the country are needed to confirm whether severe infections are more commonly multiclonal across the country.

\section{Supplementary information}

Supplementary information accompanies this paper at https://doi. org/10.1186/s12936-019-3039-9.

Additional file 1: Figure S1a. Gel electrophoresis of K1 MSP-1 allelic families' lane 1: 100 bp DNA ladder; lane 2: negative; lane 3: $130 \mathrm{bp}$; lane 4: 300 bp; lane 5, 6, 7: negative; lane 8 and 9: 280 bp; lane 10: negative control. Figure S1b. Gel electrophoresis of MAD20 MSP-1 allelic families' lane 1: 100 bp DNA ladder; lane 2: 150 bp; lane 3: 130 bp; lane 4: negative; lane 5: $180 \mathrm{bp}$; lane 6: $130 \mathrm{bp}$; lane 7 and 8: negative; lane 9: $180 \mathrm{bp}$; lane 10: 150 bp. Figure S1c. Gel electrophoresis of RO33 MSP-1 allelic families' lane 1: 100 bp DNA ladder; lane 2 and 3: 150 bp; lane 4: 180 bp; lane 5: negative control; lane 6 and 7: $150 \mathrm{bp}$.

Additional file 2: Figure S2a. Gel electrophoresis of FC27 of MSP-2 allelic families, lane 1: 100 bp DNA ladder; lane 2: 400 bp; lane 3: 350 bp; lane 4: 350 bp; lane 5: 380 bp; lane 6: 380 bp; lane 7: 320 bp; lane 8: negative; lane 9: 300 bp; lane 10: negative; lane 11: negative control. Figure S2b. Gel electrophoresis of IC/3D7 MSP-2 allelic families'lane 1: 100 bp DNA ladder; lane 2: 400 bp; lane 3: 380-500 bp; lane 4: negative; lane 5: 380-520 bp; lane 6: $380 \mathrm{bp}$; lane 7: $300 \mathrm{bp}$; lane 8: $300 \mathrm{bp}$; lane 9: negative control.

\section{Abbreviations}

DNA: deoxy-ribonucleic acid; MSP: merozoite surface protein; PCR: polymerase chain reaction; ITN: insecticide-treated bed net; bp: base pair; $\mathrm{MOI}$ : multiplicity of infection.

\section{Acknowledgements}

We would like to thank Mr. Omar Abawa from laboratory unit and the staff of Gublak Health Center for their support during data collection. We are also grateful to the participants and guardians for their agreeing to participate in the study. We would like to acknowledge Mrs. Haven Sime for providing assistance for the statistical work.

\section{Authors' contributions}

$\mathrm{HM}$ conceived the idea and designed this study. HM, KH and KM collected data and performed specimen analysis. GT and HM performed the statistical analysis. AA, GT and RJC critically reviewed the manuscript. All authors contributed to the data interpretation and manuscript writing. All authors read and approved the final manuscript.

\section{Funding}

No funding was obtained for the study.

\section{Availability of data and materials}

The datasets analysed for this study are available from corresponding author on reasonable request. All relevant data within the paper.

\section{Ethics approval and consent to participate}

The study received ethical approval from the Scientific and Ethical Review Office (SERO) of the Ethiopian Public Health Institute (EPHI). Written informed consent was obtained from the patients, parents or guardiancies.

\section{Consent for publication}

Not applicable.

\section{Competing interests}

The authors declare that they have no competing interests.

\section{Author details}

${ }^{1}$ Ethiopian Public Health Institute, Addis Ababa, Ethiopia. ${ }^{2}$ Menzies School of Health Research, Charles Darwin University, Darwin, Australia. ${ }^{3}$ Internal Medical Services, Ballarat Health Services, Ballarat, Australia.

Received: 29 September 2019 Accepted: 26 November 2019

Published online: 10 December 2019

\section{References}

1. WHO. World malaria report, 2018. Geneva: World Health Organization; 2018. https://doi.org/10.1016/S0140-6736(18)30324-6.

2. Ayalew $\mathrm{S}, \mathrm{Mamo} \mathrm{H}$, Animut A, Erko B. Assessment of current malaria status in light of the ongoing control interventions, socio-demographic and environmental variables in Jiga area, northwest Ethiopia. PLoS ONE. 2016;11:e0146214.

3. Federal Democratic Republic of Ethiopia Ministry of Health. National strategic plan for malaria prevention, control and elimination in Ethiopia, 2011-2015. Addis Ababa, Ethiopia; 2015.

4. Ashley EA, Pyae Phyo A, Woodrow CJ. Malaria. Lancet. 2018;391:1608-21.

5. WHO. Severe malaria. Trop Med Int Health. 2014;19(suppl 1):7-131.

6. Reyburn H, Mbatia R, Drakeley C, Bruce J, Carneiro I, Olomi R, Cox J, et al. Association of transmission intensity and age with clinical manifestations and case fatality of severe Plasmodium falciparum malaria. JAMA. 2005;293:1461-70.

7. Pasvol G. Cell-cell interaction in the pathogenesis of severe falciparum malaria. Clin Med J. 2001;1:495-500.

8. Kiwuwa MS, Ribacke U, Moll K, Byarugaba J, Lundblom K, Färnert A et al. Genetic diversity of Plasmodium falciparum infections in mild and severe malaria of children from Kampala, Uganda. Parasitol Res. 2013;112:1691-700.

9. A-Elbasit IE, EIGhazali G, A-Elgadir TM, Hamad AA, Babiker HA, Elbashir MI, et al. Allelic polymorphism of MSP2 gene in severe P. falciparum malaria in an area of low and seasonal transmission. Parasitol Res. 2007;102:29-34.

10. Bob NS, Diop BM, Renaud F, Marrama L, Durand P, Tall A, et al. Parasite polymorphism and severe malaria in Dakar (Senegal): a West African urban area. PLoS ONE. 2010;5(9817):e9817.

11. Rout R, Mohapatra BN, Kar SK, Ranjit M. Genetic complexity and transmissibility of Plasmodium falciparum parasites causing severe malaria in central-east coast India. Trop Biomed. 2009;26:165-72.

12. John CC, Park GS, Sam-Agudu N, Opoka RO, Boivin MJ. Elevated serum levels of IL-1 ra in children with Plasmodium falciparum malaria are associated with increased severity of disease. Cytokine. 2008;41:204-8.

13. Deitsch KW, Chitnis CE. Molecular basis of severe malaria. Proc Natl Acad Sci USA. 2012:109:10130e1.

14. Beeson JG, Drew DR, Boyle MJ, Feng G, Fowkes FJI, Richards JS. Merozoite surface proteins in red blood cells, immunity and vaccines against malaria. FEMS Microbiol Rev. 2016:40:343-72.

15. Holder AA, Blackman MJ, Burghaus PA, Chappel JA, Ling IT, McCallumDeighton N, et al. A malaria merozoite surface protein (MSP1)-structure, processing and function. Mem Inst Oswaldo Cruz. 1992;87(Suppl 3):37-42.

16. Hofmann EH, Malafronte RS, Moraes-Avila SL, Osakabe AL, Wunderlich $G$, Durham $A L$, et al. Origins of sequence diversity in the malaria vaccine 
candidate merozoite surface protein -2 (MSP-2) Amazonian of Plasmodium falciparum. Gene. 2006;376:224-30.

17. Felger I, Irion A, Steiger S, Beck HP. Genotypes of merozoite surface protein 2 of Plasmodium falciparum in Tanzania. Trans R Soc Trop Med Hyg. 1999;93(suppl 1):3-9.

18. Kiwanuka GN. Genetic diversity in Plasmodium falciparum merozoite surface protein 1 and 2 coding genes and its implications in malaria epidemiology: a review of published studies from 1997-2007. J Vector Borne Dis. 2009:46:1-12.

19. Ariey F, Hommel D, Le Scanf C, Duchemin JB, Peneau C, MercereauPuijalon O. Association of severe malaria with a specific of Plasmodium falciparum genotype in French Guiana. J Inf Dis. 2001;184:237-41.

20. Durand R, Ariey F, Fontanet A, Ranaivo L, Ranarivelo LA, Vonimpaisomihanta JA, et al. Analysis of circulating populations Plasmodium falciparum in mild and severe malaria in two different epidemiological patterns in Madagascar. Trop Med Int Health. 2008;13:1392-9.

21. Amodu OK, Oyedeji SI, Ntoumi F, Orimadegun AE, Gbadegesin RA, Olumese PE, et al. Complexity of the msp2 locus and the severity of childhood malaria, in south-western Nigeria. Ann Trop Med Parasitol. 2008;102:95-102.

22. Mohammed H, Mindaye T, Belayneh M, Kassa M, Assefa A, Tadesse M, et al. Genetic diversity of Plasmodium falciparum isolates based on MSP-1 and MSP-2 genes from Kolla-Shele area, Arbaminch Zuria District, southwest Ethiopia. Malar J. 2015;14:73.

23. Mohammed H, Kassa M, Assefa A, Tadesse M, Kebede A. Genetic polymorphism of merozoite surface protein-2 (MSP-2) in Plasmodium falciparum isolates from Pawe District, North West Ethiopia. PLoS ONE. 2017;12:e0177559.

24. Mohammed H, Kassa M, Mekete K, Assefa A, Taye G, Commons RJ. Genetic diversity of msp1, msp2 and glurp of Plasmodium falciparum isolates in Northwest Ethiopia. Malar J. 2018:17:386.

25. Alelign A, Dejene T. Current status of malaria in Ethiopia; evaluation of the burden, factors for transmission and prevention methods. Acta Parasitol Glob. 2016;7:1-6.

26. Aschale Y, Mengist A, Bitew A, Talie A. Prevalence of malaria and associated risk factors among asymptomatic migrant laborers in West Armachiho District, Northwest Ethiopia. Ther Clin Risk Manag. 2018;9:95-101.

27. Federal Ministry of Health (FMoH). National strategy plan for malaria prevention, control and elimination in Ethiopia: 2014-2020. Addis Ababa, Ethiopia; 2014.

28. WHO. Severe falciparum malaria. Trans R Soc Trop Med Hyg. 2000;94:1-18.

29. Federal Ministry of Health of Ethiopia (FMOH). National malaria guidelines. 3rd ed. Addis Ababa: Federal Ministry of Health of Ethiopia (FMOH); 2012.

30. WHO. Basic malaria microscopy, Part 1. Learner's guide. 2nd ed. Geneva: Word Health Organization; 2010.

31. Plowe CV, Djimde A, Bouare M, Doumbo O, Wellems TE. Pyrimethamine and proguanil resistance-conferring mutations in Plasmodium falciparum dihydrofolate reductase: polymerase chain reaction methods for surveillance in Africa. Am J Trop Med Hyg. 1995;52:565-8.

32. Vafa M, Troye- Blomberg M, Anchang J, Garcia A, Migot-Nabias F. Multiplicity of Plasmodium falciparum infection in asymptomatic children In Senegal, relation of transmission, age, and erythrocyte variants. Malar J. 2008;9:17.

33. Ntoumi F, Ngoundou-Landji J, Lekoulou F, Luty A, Deloron P, Ringwald P. Site-based study on polymorphism of Plasmodium falciparum msp-1 and msp-2 genes in isolates from two villages in Central Africa. Parassitologia. 2000;42:197-203.
34. Bouyou-Akotel MK, M'Bondoukwe NP, Mawili-Mboumba DP. Genetic polymorphism of merozoite surface protein-1 in Plasmodium falciparum isolates from patients with mild and severe malaria in Libreville, Gabon. Parasite. 2015;22:12.

35. Hamid MAM, Elamin AF, Ali-Albsheer MM, Abdalla AA, Mahgoub NS, Mustafa SO, et al. Multiplicity of infection and genetic diversity of Plasmodium falciparum isolates from patients with uncomplicated and severe malaria in Gezira State, Sudan. Parasit Vectors. 2016;9:362.

36. Robert F, Ntoumi F, Angel G, Candito D, Rogier C, Fandeur T, et al. Extensive genetic diversity of Plasmodium falciparum isolates collected from patients with severe malaria in Dakar. Trans R Soc Trop Med Hyg. 1996:90:704-11.

37. Hamid MM, Mohammed SB, El Hassan IM. Genetic diversity of Plasmodium falciparum field isolates in Central Sudan inferred by PCR genotyping of merozoite surface protein 1 and 2. Am J Med Sci. 2013;5:95-101.

38. Mayengue $\mathrm{Pl}$, Ndounga $\mathrm{M}$, Malonga FV, Bitemo M, Ntoumi F. Genetic polymorphism of merozoite surface protein 1 and merozoite surface protein 2 in Plasmodium falciparum isolates from Brazzaville, Republic of Congo. Malar J. 2011;10:276.

39. Funwei RI, Thomas BN, Falade CO, Ojurongbe O. Extensive diversity in the allelic frequency of Plasmodium falciparum merozoite surface proteins and glutamate-rich protein in rural and urban settings of southwestern Nigeria. Malar J. 2018;17:1.

40. Felger I, Maire M, Bretscher MT, Falk N, Tiaden A, Sama W, et al. The dynamics of natural Plasmodium falciparum infections. PLOS ONE. 2012;7:e45542.

41. Oyedeji SI, Awobode HO, Kun J. Limited genetic diversity and low multiplicity of Plasmodium falciparum infection in children with severe malaria in Lafia in North-central Nigeria. J Exp Clin Med. 2013:5:143-7.

42. Mayeungue PI, Luty AJ, Rogier C, Baragatti M, Kremsner PG, Ntoumi F. The multiplicity of Plasmodium falciparum infections is associated with acquired immunity to asexual blood stage antigens. Microbes Infect. 2009:11:108-14.

43. Smith T, Beck HP, Kitua A, Mwankusye S, Felger I, Fraser-Hurt N, et al. Age dependence of the multiplicity of Plasmodium falciparum infections and other malariological indices in an area of high endemicity. Trans R Soc Med Hyg. 1999;93(Suppl 1):15-20.

44. Konate L, Zwetyenga J, Rogier C, BischoffE, Fontenille D, Tall A, et al. Variation of Plasmodium falciparum msp 1 block 2 and $m s p 2$ allele prevalence and of infection complexity in two neighbouring Senegalese villages with different transmission conditions. Trans R Soc Trop Med Hyg. 1999:93(Suppl 1):21-8.

45. Ogouye'mi-Hounto A, Gazard DK, Ndam N, Topanou E, Garba O, Elegbe $P$, et al. Genetic polymorphism of merozoite surface protein-1 and merozoite surface protein-2 in Plasmodium falciparum isolates from children in South of Benin. Parasite. 2013;20:37.

46. Mueller I, Schoepflin S, Smith TA, Benton KL, Bretscher MT, Lin E, et al. Force of infection is a key to understanding the epidemiology of Plasmodium falciparum malaria in Papua New Guinean children. Proc Nat Acad Sci USA. 2012;109:10030-5.

47. Färnert A, Lebbad M, Faraja I, Rooth I. Extensive dynamics of Plasmodium falciparum densities, stages and genotyping profiles. Malar J. 2008;7:241.

\section{Publisher's Note}

Springer Nature remains neutral with regard to jurisdictional claims in published maps and institutional affiliations. 